\title{
GUÅHAN, THE PACIFIC AND DECOLONIAL POETRY
}

\author{
[Received May 1st 2019; accepted July 4th 2019 - DOI: 10.21463/shima.13.2.05] \\ Craig Santos Perez \\ University of Hawai'i <csperez@hawaii.edu>
}

KEYWORDS: Guåhan (Guam), Chamoru, decolonial poetry

\section{Introduction}

I am an indigenous Chamoru from the Western Pacific Island of Guåhan (Guam). I was raised in the village of Mongmong, and my family clan name is Gollo. When I was 15 years old, my family migrated to California, where I lived for 15 years, completing my high school, undergraduate, and graduate education. I moved to Hawai' $i$ ten years ago, where I now teach poetry and creative writing in the English department at the University of Hawai'i, Mānoa. I begin this short essay with my genealogical and geographical background because living in and traveling between the imagined archipelago of Guåhan, Hawai'i, and California have shaped my poetry and poetic practice.

My sea-faring Chamoru ancestors first peopled Guåhan millennia ago, developing a complex society based on the value of inafa'maolek, which is the Chamoru belief that all peoples, spirits, animals, plants, lands, and waters are interconnected, and thus we should act with respect, consent, and mutual care. Chamoru society was indelibly changed in the 16th century, when Guåhan was "discovered" by Magellan and consequently missionised and colonised by the Spanish empire. The island became an important Spanish mission, garrison, and refueling station for the lucrative Acapulco-Manila Galleon trade route. After the Spanish-American War of 1898, Guåhan and other Spanish colonies were annexed by the United States. A series of US Supreme Court cases, known as the 'Insular Cases' (1901-04), established a new political status, the "unincorporated territory," which refers to a territory that is owned by the United States but is not fully incorporated as a state of the nation. To this day, Guåhan has remained in this unincorporated, colonial status, depriving the Chamoru people of our rights to self-determination and sovereignty.

Over the last 120 years, the United States has treated Guåhan as a military base in the AsiaPacific region from which to project power (the island is often referred to as the "Tip of the Spear"), which has resulted in the expropriation of land to construct multiple bases for the Army, Marines, Navy, and Air Force. Today, the military occupies a third of the entire landmass of Guåhan, having displaced many Chamoru families from their land (including my father's family). The massive amount of militarisation on Guåhan has led some to describe the island as an "unsinkable aircraft carrier" and "USS Guam." While the military has alienated Chamorus from the land and deforested thousands of acres to construct bases, it has also contaminated the island with chemicals, military waste, and nuclear radiation, which have caused high rates of cancer and other diseases amongst my people.

Shima <www.shimajournal.org> ISSN: 1834-6057 
As a child, I remember the barbed wire military fences that snake throughout the island, separating us from our land. I remember the fighter jets roaring above my elementary school during recess, leaving chem-trails across the sky. I remember seeing the massive aircraft carriers and warships moving like steel leviathans on the horizon as we swam in the ocean. I remember all the soldiers at the beaches and restaurants. I remember the tanks and military vehicles moving slowly down Guåhan's main thoroughfare: Marine Corps Drive. Despite the violence and environmental devastation wrought by American militarism, Chamorus (and Pacific Islanders in general) have the highest per capita rates of enlistment than other population within the United States, and Guåhan has one of the highest per capita rates of enlistment than other states and territories. There are complex reasons for Chamoru involvement in militarism, the main reason being economic: the US military is the largest employer on Guåhan and military service is the most visible and reliable form of economic advancement on Guåhan. Chamorus have served and died in all American wars since the Korean war. In my own family, my dad was in the Army (a Vietnam veteran), my grandfather was in the Navy, my godfather in the Marines, and many of my uncles and cousins have served in active duty and in the reserves. Additionally, I have other family members who have worked in military related industries on Guåhan. Militarism has not only impacted our lands and waters, but it has also shaped our families and cultural identities.

The colonisation and militarisation of my home island has been a major theme since I started writing poetry. Since 2008 , I have been working on a multi-book series entitled, from unincorporated territory. Thus far, four books have been published, all of which explore what it means to be from Guåhan, what it means to be from a modern-day colony of the American empire, what it means to witness the military pollute the land and my people's bodies, what it means to be from a deeply militarised indigenous culture. My poetry draws from Pacific Islander, indigenous, diasporic, ecocritical, and post/decolonial literary traditions. I envision my work as writing Guåhan and the Pacific-places that have often been erased from global historiographies--into existence. The poems included in this special folio will appear in the fifth book of my from unincorporated series, forthcoming in 2022. The first poem, 'The Fifth Maps,' explores the theme of mapping, geographic imaginaries, and archipelagoes. The second and third poems, 'Family Trees' and 'Memorial Day in the Pacific,' addresses the impact of militarism on Pacific Islander culture and the environment. The final poem, 'Storm Tracking,' focuses on the devastation wrought by increased hurricanes in the Pacific due to climate change, and the subsequent exploitation of disaster capitalism and colonialism. Taken together, I hope these poems will contribute to our understanding of islands, archipelagoes, and coloniality. 


\section{The Fifth Map}

The first map my dad hangs in the hallway is an aerial view of Guam.

The island nearly fills the entire space. "Where is our village?" I ask him. "In the center," he says. "Here: Mongmong." I whisper the names of other villages:

"Hagatna, Barrigada, Tumon, Dededo, Agat..." I once imagined these places as completely separate, but now I see they're only different parts of the same tropical body.

2

The second map my dad hangs in the hallway is an aerial view of the Marianas archipelago. I count 15 islands extending in a vertical crescent. I recognize the shape of Guam, the largest and southernmost in the linked chain. My dad pronounces the names of the northern islands: "Rota, Aguijan, Tinian, Saipan, Farallon de Medinilla, Anatahan, Sarigan, Guguan, Alamagan, Pagan, Agrihan, Asuncion, Maug, and Farallon de Pajaros." I tell him:

"They look like the beads of a rosary."

3

The third map my dad hangs in the hallway is an aerial view of Micronesia.

“Micro- means 'tiny,"' he says. "And 'nesia' means 'islands." Two thousand dots scattered across the Western Pacific.

My dad points: "Here's the Marianas, and here's Palau, Yap, Chuuk, Pohnpei, Kosrae, the Marshalls, Nauru, and Kiribati."

The archipelagoes resemble constellations.

"Are the people there Chamorro too?"

I ask him. "No," he answers.

"But they're our cousins." 
The fourth map my dad hangs in the hallway is an aerial view of the Pacific Ocean, rimmed by the Americas and Asia.

Countless archipelagoes divided into three regions:

Micronesia, Melanesia, and Polynesia.

My dad traces a triangle between Hawai' $i$,

Easter Island (Rapa Nui), and New Zealand.

"This is Polynesia," he says. "Poly- means many."

Then he draws an imaginary circle around

Papua New Guinea, the Solomon Islands,

Fiji, Vanuatu, and New Caledonia.

"This is Melanesia," he says. "Mela- means black."

The ocean, connecting these vast distances

looks like a blue continent. "Remember,"

he says. "We're all relatives."

5

My dad never hung a fifth map in the hallway.

I first see it when I travel, as an adult, to Taiwan.

The tour guide shows me an aerial view

of Austronesia. “'Austro- means 'south,"” she says.

A highlighted area, the shape of a full sail, stretches

from Madagascar to the Malay peninsula

and Indonesia, north to the Philippines and Taiwan, then traversing Micronesia and Polynesia.

"Austronesians migrated to escape war, famine, disease, and rising seas," she says.

It's difficult to imagine that 400 million people

alive today, who speak over 1000 different languages, all descend from the same mother tongue, the same genetic family. I examine the map closely, navigating beyond the violent divisions of national and maritime borders, beyond the scarred latitudes and longitudes of empire, until we arrive at the cartography of our most expansive legends and deepest routes. 


\section{Family Trees}

written for the 2016 Guam Educators Symposium on Soil and Water Conservation

Before we enter the jungle, my dad asks permission of the spirits who dwell within. He walks slowly, with care, to teach me, like his father taught him, how to show respect. Then he stops and closes his eyes to teach me how to listen. Ekungok, as the winds exhale and billow the canopy, tremble the understory, and conduct the wild orchestra of all breathing things.

"Niyok, Lemmai, Ifit, Yoga', Nunu," he chants in a tone of reverence, calling forth the names of each tree, each elder, who has provided us with food and medicine, clothes and tools, canoes and shelter. Like us, they grew in dark wombs, sprouted from seeds, were nourished by the light. Like us, they survived the storms of conquest. Like us, roots anchor them to this island, giving breath, giving strength to reach towards the Pacific sky and blossom.

3

"When you take," my dad says, "Take with gratitude, and never more than what you need." He teaches me the phrase, "eminent domain," which means "theft," means "to turn a place of abundance into a base of destruction." The military uprooted trees with bulldozers, paved the fertile earth with concrete, and planted toxic chemicals and ordnances in the ground. Barbed wire fences spread like invasive vines, whose only fruit are the cancerous tumors that bloom on every branch of our family tree. 
Today, the military invites us to collect plants and trees within areas of Litekyan slated to be cleared for impending construction. Fill out the appropriate forms and wait 14 business days for a background and security check. If we receive their permission, they'll escort us to the site so we can mark and claim what we want delivered to us after removal. They say this is a benevolent gesture, but why does it feel like a cruel reaping?

\section{5}

One tree my dad never showed me is the endangered hayun lågu, the last of which is struggling to survive in Litekyan its only home. Today, the military plans to clear the surrounding area for a live firing range, making the tree even more vulnerable to violent winds, invasive pests, and stray bullets. Don't worry, they say. We'll build a fence around the tree. They say this is an act of mitigation, but why does it feel like the disturbed edge of extinction?

6

Ekungok, ancient whispers rouse the jungle! Listen, oceanic waves stir against the rocks! Ekungok, i taotao'mona call us to rise! Listen, i tronkon Yoga' calls us to stand tall! Ekungok, i tronkon Lemmai calls us to spread our arms wide! Listen, i tronkon Nunu calls us to link our hands! Ekungok, i tronkon Ifit calls us to be firm! Listen, i tronkon Niyok calls us to never break! Ekungok, i halom tano' calls us to surround $i$ hayun lågu and chant: "We are the seeds of the last fire tree! We are the seeds of the last fire tree! We are the seeds of the last fire tree! Ahe'! No! We do not give you permission!" 


\section{Memorial Day in the Pacific}

america declares a federal holiday, we mourn daily. america says 3-day weekend, we recite 9-day prayers. america barbecues, no matter how much we cook, some chairs around the table remain empty. america marks the beginning of summer, grief is our endless sea -son. america marches in parades, we dust photo albums. america blooms flowers and fireworks, we wilt and ashes. america observes a moment of silence, we miss their voices. america says national cemetery, we visit mass graves. america waves its flag, our flags are tightly folded. america sings "land of the free," we whisper "continent of thieves." america says "recruiter's paradise," we say "home." america dons uniforms, we covered in shrouds. america pledges allegiance, our heartbeats are a continuous gun salute. america recounts the names of the dead, we count stolen generations. america ignores its veterans, our kin commit suicide. america thanks us for our ultimate sacrifice, we bow before our cruel god. america commands, "be all you can be," we ask: when will we ever be whole? 


\section{Storm Tracking}

This is when the warm ocean gives birth to a cycloneThis is when we give a human name to weather we can't control-

This is when wind triggers warning system and rain drums violent refrain--

This is when we hold our children close

and whisper: "don't be scared, we won't let go"-

This is when flood waters whisper: "let go"-

This is when the world

finally sees us:

only after the eye

$$
\text { of a storm }
$$

sees us-

This is when we chant: "we will overcome"-

This is when trauma attracts tourism--

This is when politicians siphon aid and corporations promise "green development"-

This is when public utilities and schools are closed or privatizedThis is when disaster justifies

another military and colonial coup-

This is when we chant: "we will never forget"

This is when the world forgets us

This is when we migrate with or without dignity-

This is when counting donations becomes prayer-

when counting bodies becomes prayer-

when counting days until the next storm becomes prayerThis is when our sea of vulnerable islands

becomes an archipelago of prayer- 